\title{
Electromyographic Activity of Gluteus Maximus Muscle in Nonspecific Chronic Low Back Pain
}

\author{
HATEM Y. MOHAMMED, M.Sc.; REHAM H. DIAB, Ph.D. and RANIA R. MOHAMED, Ph.D. \\ The Department of Basic Sciences, Faculty of Physical Therapy, Cairo University, Egypt
}

\begin{abstract}
Background: Nonspecific chronic low back pain is a common problem that can cause economic and social problems for an individual. Although there were alot of studies have reported the changes in the gluteus maximus activity in nonspecific chronic low back pain patients but it still debated.

Aim of Study: This study was conducted to investigate electromyographic activity of gluteus maximus muscle in nonspecific chronic low back pain male patients.

Subjects and Methods: Thirty nonspecific chronic low back pain male patients and 30 healthy male subjects with age from 20 to 40 years old with body mass index less than $30 \mathrm{~kg} / \mathrm{m}^{2}$ were recruited and assigned into 2 groups. Assessment was conducted by surface electromyography to assess gluteus maximus activity. Normalized root mean square of gluteus maximus muscle was collected and analyzed by SPSS version (24).

Results: There were significance decrease in electromyographic activity of right and left gluteus maximus in the study group when compared to control with $p$-values $>0.005$.

Conclusion: There was a decrease in the activity of the gluteus maximus in nonspecific chronic low back pain male patients when compared to the control group.
\end{abstract}

Key Words: Gluteus maximus muscle-Nonspecific chronic low back pain - Electromyography.

\section{Introduction}

NON-SPECIFIC low back pain is expressed as low back pain not related to a specific pathology. Low back pain became one of the biggest problems for public health systems in the western world during the second half of the 20 th century, and now seems to be extending worldwide. It has been reported that imbalance in the length, function, and strength of the trunk and hip muscles can lead to low back pain $[1,2]$

Correspondence to: Dr. Hatem Y. Mohammed,

The Department of Basic Sciences, Faculty of Physical Therapy, Cairo University, Egypt
Patients with CLBP disorders had abnormal adaptations resulting in movement and control impairments, leading to either excessive or impaired dynamic spinal stability and loading. This in turn induces pain. Changes in motor control may cause abnormal muscle activation (i.e. timing or rate of force development), affecting subject's ability to perform adequate automatic movement patterns $[3,4]$

Prone Hip Extension (PHE) test is frequently used and accepted test for assessment of lumbopelvic stability and muscle recruitment pattern of posterior oblique sling muscles in patients with CLBP. There was a study that examined the activity of posterior oblique sling (latissimus dorsi, Erector Spine (ES), gluteus maximus and biceps femoris (BF)) during PHE test. They found greater muscle activation patterns of contralateral LD and decreased activity of GM in women with CLBP when compared to matched controls. They thought that women with CLBP with decreased activity of GM compensate for faulty movements, as rotation of thoracolumbar spine during PHE test through over activity of LD [5]

\section{Subjects and Methods}

Thirty male patients and 30 male healthy subjects aged from 20-40 years old were recruited from outpatient clinics, Faculty of Physical Therapy, Cairo University and assigned into study group (A) and control group (B) in the period from June 2018 to September 2018. Before the experiment, the purpose and procedures of the study were fully explained to all subjects, and all subjects subsequently voluntarily agreed to enroll in the present study. 
General characteristics of the subjects were measured, including age ( $29 \pm 5.53$ years) for group $\mathrm{A}$ and (3 $1.03 \pm 6.31$ years) for group $\mathrm{B}$, height $(169.73 \pm 5.84 \mathrm{~cm})$ for group $\mathrm{A}$ and $(171 \pm 6.05 \mathrm{~cm})$ for group B, weight $(70.94 \pm 7.39 \mathrm{~kg})$ for group A and $(70.66 \pm 9.95 \mathrm{~kg})$ for group B and BMI $(24.61 \pm$ 2.18 ) for group $A$ and $(24.12 \pm 2.76)$ for group $B$. Subjects who had history of any shoulder pathology or surgery, cardiovascular disease, leg limb discrepancy, thoracic and/or shoulder girdle pain, congenital pathology affecting spine or shoulder, any neurological disorder, non-mechanical LBP (e.g., fracture, malignancy, infection, spinal dislocation), difficulty to perform the PHE task because of weakness in the GM or the test provokes pain, BMI 30 or higher as fat tissue may decrease the ability to measure surface EMG activity were excluded from the study.

\section{Instrumentation:}

\section{EMG Surface apparatus:}

MyoTrac Infiniti, Handheld EMG model SA9800 made in Canada is a state of the art modular EMG data collection system [6]

\section{Methods:}

Electrode placement and procedure for recording of EMG activity: Before placement of the EMG electrodes, the skin at the anatomic landmarks will be shaved (if required), rubbed and cleaned with isopropyl alcohol $70 \%$ to remove excess oils and debris. The active and reference electrodes will be placed on the muscle belly oriented parallel to the muscle fiber away from the tendon and muscle edges. The ground electrode will be placed on any bony prominence distal to the other electrodes.

\section{Measurements:}

For GM, the active electrode was placed at half the distance between the greater trochanter and second sacral vertebra and at an oblique angle at, or slightly above, the level of the trochanter, the reference electrode will placed beside the active one parallel to the fibers of the muscle with a distance equal to the size of electrode, the ground electrode was placed distally on the greater trochanter [6].

Before testing, all subjects were informed about active PHE and given a sufficient familiarization period to practice before the investigation. All procedures for EMG measurements were performed with the subjects in the prone position on a therapeutic table with a firm mattress. The subjects were asked to lie prone with their arms at their side and with a neutral position of the pelvis and hip joint. We set the target angle at 10 degree using goniometer to control the amount of hip extension and an adjustable bar was placed at this level and provided feedback. Feedback information at 10 degree of hip extension also was given to the subjects by verbal instruction.

The participant was instructed to extend his leg from neutral to about 10 degree while keeping the knee straight. When the hip was placed at 10 degree of extension, the participant was asked to hold this position for 5 seconds. The position of the pelvis was supervised visually during the PHE task to ensure that the subject maintained a neutral pelvis position, hip extension, and knee extension. If visible hip rotation movement or pelvic rotation was observed, the data were excluded. The system automatically measured 3 trials each trial will take 5 second with a 5 second rest in between then the average value was calculated [5]

The signals was amplified and then the Root Mean Square (RMS) will be calculated. The average RMS of the EMG signal during each PHE task trial was calculated and expressed as a percentage of the normalized value. The mean percent normalized value of three repetitions was determined for EMG data analysis [5].

For the submaximal contraction of GM, the subject was asked to lift both knee $5 \mathrm{~cm}$ off the examination table while the knees were flexed at 90 and hold them for 5 seconds in a prone position. It was recommended to avoid maximal contractions of the GM muscle, because reproduction of pain on testing would have possibly invalidated the use of the RMS values for normalization [7]

\section{Data analysis:}

Measured data were analyzed and their mean values and standard deviation were calculated. Unpaired sample- $t$-test was used to compare variables that measured in patients with NSCLBP and matched controls. All statistical significance levels were $\alpha=0.05$.

\section{Results}

\section{Demographic data:}

The descriptive statistics, independent $t$-test for the demographic data for both groups are presented in (Table 1). Study group A: Consisted of 30 NSCLBP patients with $29 \pm 5.53$ years for age, $70.94 \pm 7.39 \mathrm{Kg}$ for weight, $169.73 \pm 5.84 \mathrm{~cm}$ for height and BMI was $24.61 \pm 2.18 \mathrm{~kg} / \mathrm{m} 2$. 
Control group B: Consisted of 30 subjects with $31.03 \pm 6.31$ years for age, $70.66 \pm 9.95 \mathrm{Kg}$ for weight, $171 \pm 6.05 \mathrm{~cm}$ for height and BMI was $24.12 \pm 2.76$ $\mathrm{kg} / \mathrm{m}^{2}$.

Table (1): Descriptive and inferential statistics of age, weight, height and BMI between groups.

\begin{tabular}{|c|c|c|c|c|}
\hline & & Con & arison & \\
\hline & & $t$-value & $p$-value & \\
\hline $\begin{array}{c}\text { Age (years): } \\
\text { Group A } \\
\text { Group B }\end{array}$ & $\begin{array}{l}29 \pm 5.53 \\
31.03 \pm 6.31\end{array}$ & -1.327 & 0.190 & NS \\
\hline $\begin{array}{c}\text { Weight }(\mathrm{kg}) \text { : } \\
\text { Group A } \\
\text { Group B }\end{array}$ & $\begin{array}{l}70.94 \pm 7.39 \\
70.66 \pm 9.95\end{array}$ & 0.124 & 0.902 & NS \\
\hline $\begin{array}{c}\text { Height }(\mathrm{cm}): \\
\text { Group A } \\
\text { Group B }\end{array}$ & $\begin{array}{l}169.73 \pm 5.84 \\
171 \pm 6.05\end{array}$ & -0.824 & 0.413 & NS \\
\hline $\begin{array}{c}B M I\left(\mathrm{~kg} / \mathrm{m}^{2}\right) \\
\text { Group A } \\
\text { Group B }\end{array}$ & $\begin{array}{l}24.61 \pm 2.18 \\
24.12 \pm 2.76\end{array}$ & 0.772 & 0.444 & NS \\
\hline $\begin{array}{ll}\mathrm{SD} & : \text { Stan } \\
t \text {-value } & : \text { Stati } \\
p \text {-value } & : \text { Prob } \\
\mathrm{S} & : \text { Sign } \\
\mathrm{NS} & : \text { Non- } \\
\mathrm{BMI} & : \text { Body } \\
* & : \text { Sign }\end{array}$ & $\begin{array}{l}\text { Deviation. } \\
\text { t-test. } \\
\text { y. } \\
\text { che. } \\
\text { ificance. } \\
\text { ss Index. } \\
\text { nt at alpha leve }\end{array}$ & & & \\
\hline
\end{tabular}

\section{RMS of gluteus maximus muscle:}

As presented in (Table 2) and illustrated in Fig. (1) there was statistically significant difference between RMS of right gluteus maximus value of both groups (A and $\mathrm{B}$ ). The $t$-value was -15.96 and $p$-value was .0001, also there was statistically significant difference between RMS of left gluteus maximus values of both groups (A and B) where the $t$-value was -24.15 and $p$-value was 0.0001 .

Table (2): Independent $t$-test between both groups (A and B) for RMS of gluteus maxmus muscle.

\begin{tabular}{lll}
\hline & \multicolumn{2}{c}{ RMS of gluteus maxmus muscle } \\
\cline { 2 - 3 } Independent $t$-test & \multicolumn{1}{c}{ Rt side } & Lt side \\
\hline Group A mean \pm SD & $48.24 \pm 15.92$ & $41.47 \pm 11.53$ \\
Group B mean \pm SD & $95.78 \pm 3.55$ & $94.32 \pm 3.25$ \\
Mean difference & -47.53 & -52.85 \\
$t$-value & -15.96 & -24.15 \\
$p$-value & 0.0001 & 0.0001 \\
$\mathrm{~S}$ & $\mathrm{SD}$ & $\mathrm{SD}$ \\
\hline $\mathrm{SD} \quad:$ Standard Deviation. & \\
$t$-value & Statistic $t$-test. & \\
$p$-value : Probability. & & \\
$\mathrm{S}$ & : Significance. & \\
$\mathrm{NS} \quad$ Non-Significance. & \\
$\mathrm{BMI} \quad$ : Body Mass Index. & \\
$*$ & : Significant at alpha level $<0.05$. &
\end{tabular}

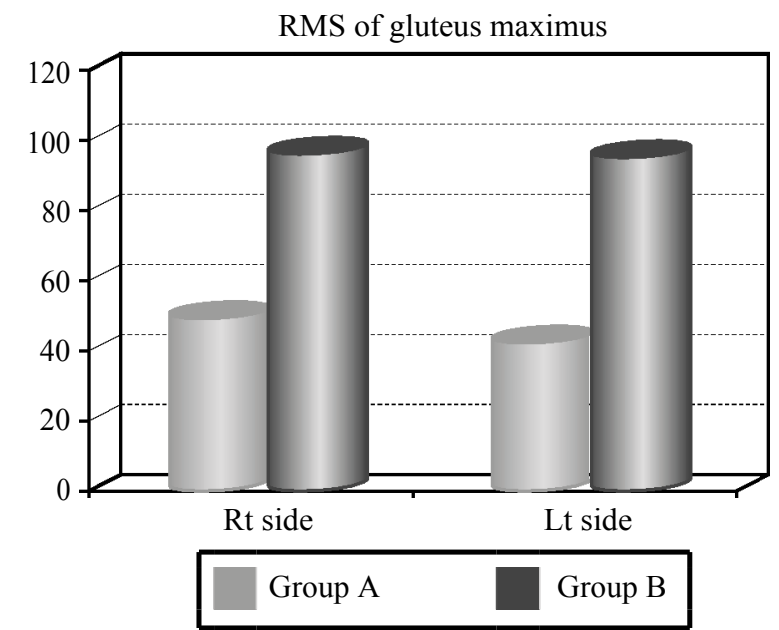

Fig. (1): Mean RMS of glutues maxmus muscle Rt and Lt sides for both groups.

\section{Discussion}

In our study, there was decreased activity of normalized EMG signals in GM muscle in NSCLBP male patients when compared to matched control group. GM considered being part of the posterior oblique sling that support the thoracolumbar fascia and lumbopelvic region. Any affection to the lower back area may affect the activity of posterior oblique sling muscles $[\mathbf{8 , 9}]$.

Also decreased activity of GM muscle may follow the pain adaptation model that predict reduction in activity of motor neuron output of agonist muscle due to pain (muscle that become shorter) and increased activity in antagonist muscles (the muscle that elongated), that interpretation is based on the predicted effects on kinematics. This leads to a reduction in $\mathrm{MVC}$, and in the range and velocity of movement. All these adaptations aiming to protect the injured part against more injury $[10,11]$

This study agreed with our results which stated that there is a reduced activity of gluteus maximus muscles during forward bending in patients with chronic low back pain, their explanation was that CLBP avoid using their back muscles in everyday life tasks due to fear of pain. This leads to atrophy of the back muscles, especially in the multifidus muscle and will lead to more pain and enhance the avoidance cycle. So other muscle groups that are functionally work together with lumbar Para spinal muscles, such as gluteus maximus, are affected by deconditioning [12-14]

Some studies found a significant delayed onset of Gluteus Maximus (GM) activity while performing PHE test in patients with low back pain compared to healthy individuals $[15,16]$ 
There was a significantly decrease of the gluteus maximus activity relative to the semitendinosus as a result of increased activity of hip flexors during prone hip extension that may result into increase anterior pelvic tilting in healthy subjects during PHE task. These results may indicate an imbalance between the agonist and antagonist hip muscles and delayed trunk muscle onset that may lead to increase in motion of the lumbopelvic region [3] .

Our study is in line with Himmelreicha et al., that suggested that low back disorders are associated with changes of the amount and duration of gluteus maximus activation under different gait conditions (level and $10^{\circ}$ incline) and a stair climb task. The alterations may be due to compensation to increase lumbo-pelvic stabilization [17].

Also Feeney et al., found that individuals with SIJD have significally reduced activation of GM during walking in loading phase of the affected leg when compared to the other leg [18]

In contrast Kim et al., found that there was increased activity of gluteaus maximus muscle during prone hip extension which is contradict with our study. His explanation was that in women increased activity of the GM with the other muscles included in the POS help to give more support to the pelvic and thoracolumbar region during PHE task in women with CLBP. His sample was females only but our sample was males so it may affect the results as in pregnant women during ASLR, the muscles activation of hip flexors increased to compensate the laxity in ligaments supporting the pelvic so increasing the activity help to increase stability of lumbopelvic region during ASLR, Therefore, gender may affect the result of the study [19.5],

Also we are in contrast with this study than show there is no statistically difference in the normalized electrical activity of the GM during PHE task in women with chronic low back pain. Although there was slightly increase in the GM activity but not significally difference. Pain is excluded to be a limiting factor to perform PHE, so, there is no direct effects of pain, but nocioception may affect muscle activity. Also this study conducts only on females so it bay be affected by gender [20]

In contrast Guimarães et al., found that there was no significant differences between LBP patients and matched control group in latencies, durations and amount of EMG activation GM muscle during active prone hip extension task. The results of raw data of EMG was normalized using peak values obtained during PHE movement not using the sub maximal isometric voluntary contraction, so it may affect the results [21].

\section{Conclusion:}

There was an influence of nonspecific chronic low back pain on the electromyographic activity of gluteus maximus muscle.

\section{References}

1- SILFIES S.P., SQUILLANTE D., MAURER P., WESTCOTT S. and KARDUNA A.R.: "Trunk muscle recruitment patterns in specific chronic low back pain populations". Clinical Biomechanics, 20 (5): 465-73, 2005.

2- KAHLAEE A.H., GHAMKHAR L. and ARAB A.M. "Effect of the Abdominal Hollowing and Bracing Maneuvers on Activity Pattern of the Lumbopelvic Muscles During Prone Hip Extension in Subjects With or Without Chronic Low Back Pain: A Preliminary Study". Journal of Manipulative and Physiological Therapeutics, 40 (2): 106-17, 2016

3- VOGT L., PFEIFER K. and BANZER W.:" Neuromuscular control of walking with chronic low-back pain". Manual therapy, 8 (1): 21-8, 2003.

4- SULLIVAN P.O.: "Diagnosis and classification of chronic low back pain disorders: Maladaptive movement and motor control impairments as underlying mechanism". Manual Therapy, 10: 242-55, 2005.

5- KIM J.W., KANG M.H. and OH J.S.: "Patients With Low Back Pain Demonstrate Increased Activity of the Posterior Oblique Sling Muscle During Prone Hip Extension". PM and R, 6 (5): 400-5, 2014.

6- PIROUZI S., HIDES J., RICHARDSON C., DARNELL R. \& TOPPENBERG R.: "Low back pain patients demonstrate increased hip extensor muscle activity during standardized submaximal rotation efforts". Spine, 31 (26): E999-E1005, 2006.

7- DANKAERTS W., O'SULLIVAN P.B., BURNETT A.F., STRAKER L.M. and DANNEELS L.A.: "Reliability of EMG measurements for trunk muscles during maximal and sub-maximal voluntary isometric contractions in healthy controls and CLBP patients". Journal of Electromyography and Kinesiology, 14 (3): 333-42, 2004.

8- CARVALHAIS V.O., De MELO OCARINO J., ARAÚJO V.L., SOUZA T.R., SILVA P.L.P. and FONSECA S.T.: "Myofascial force transmission between the latissimus dorsi and gluteus maximus muscles: An in vivo experiment". Journal of Biomechanics, 46 (5): 1003-7, 2013.

9- TAGHIZADEH S., PIROUZI S., HEMMATI L., KHALEDI F. and SADAT A.: "Clinical Evaluation of Scapular Positioning in Patients With Nonspecific Chronic Low Back Pain: A Case-Control Study". Journal of Chiropractic Medicine, 16 (3): 195-8, 2017.

10- DIEËN J.H., SELEN L.P. and CHOLEWICKI J.: "Trunk muscle activation in low-back pain patients, an analysis of the literature". Journal of Electromyography and Kinesiology, 13 (4): 333-51, 2003.

11- LUND J.P., DONGA R., WIDMER C.G. and STOHLER C.S.: "The pain-adaptation model: A discussion of the relationship between chronic musculoskeletal pain and 
motor activity". Canadian Journal of Physiology and Pharmacology, 69 (5): 683-94, 1991.

12- COOPER R.G., FORBES W.S.C. and JAYSON M.I.V.: "Radiographic demonstration of paraspinal muscle wasting in patients with chronic low back pain". Rheumatology, 31 (6): 389-94, 1992.

13- KANKAANPÄÄ M., TAIMELA S., LAAKSONEN D., HÄNNINEN O. and AIRAKSINEN O.: "Back and hip extensor fatigability in chronic low back pain patients and controls". Archives of Physical Medicine and Rehabilitation, 79 (4): 412-7, 1998.

14- LEINONEN V., KANKAANPÄÄ M., AIRAKSINEN O. and HÄNNINEN O.: "Back and hip extensor activities during trunk flexion/extension: Effects of low back pain and rehabilitation". Archives of physical medicine and rehabilitation, 81 (1): 32-7, 2000.

15- BRUNO P.A. and BAGUST J.: "An investigation into motor pattern differences used during prone hip extension between subjects with and without low back pain". Clinical Chiropractic, 10 (2): 68-80, 2007.

16- BRUNO P.A., BAGUST J., COOK J. and OSBORNE N.: "An investigation into the activation patterns of back and hip muscles during prone hip extension in non-low back pain subjects": Normal vs. abnormal lumbar spine motion patterns. Clinical Chiropractic, 11 (1): 4-14, 2008.
17-HIMMELREICH H., VOGT L. and BANZER W.: "Gluteal muscle recruitment during level, incline and stair ambulation in healthy subjects and chronic low back pain patients". Journal of Back and Musculoskeletal Rehabilitation, 21 (3): 193-9, 2008.

18- FEENEY D.F., CAPOBIANCO R.A., MONTGOMERY J.R., MORREALE J., GRABOWSKI A.M. and ENOKA R.M.: "Individuals with sacroiliac joint dysfunction display asymmetrical gait and a depressed synergy between muscles providing sacroiliac joint force closure when walking". Journal of Electromyography and Kinesiology, 43: 95103, 2018.

19- GROOT M., POOL-GOUDZWAARD A.L., SPOOR C.W and SNIJDERS C.J.: "The active straight leg raising test (ASLR) in pregnant women: Differences in muscle activity and force between patients and healthy subjects". Manual Therapy, 13 (1): 68-74, 2008.

20- ARAB A.M., GHAMKHAR L., EMAMI M. and NOURBAKHSH M.R.: "Altered muscular activation during prone hip extension in women with and without low back pain". Chiropractic \& Manual Therapies, 19 (1): 18, 2011.

21- GUIMARÃES C.Q., SAKAMOTO A.C., LAURENTINO G.E. \& TEIXEIRA-SALMELA L.F.: "Electromyographic activity during active prone hip extension did not discriminate individuals with and without low back pain". Brazilian Journal of Physical Therapy, 14 (4): 351-7, 2010.



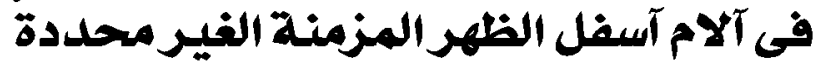

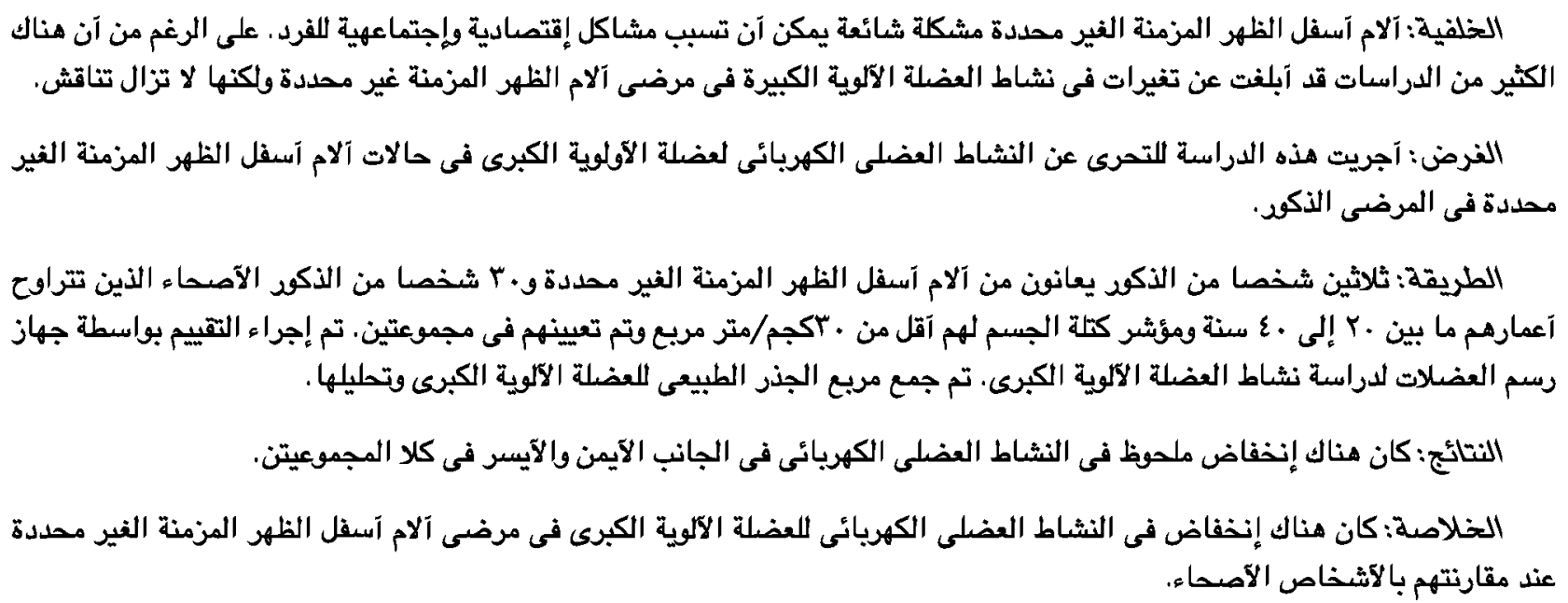

